\title{
Streamlining the Formation of Virtual Enterprises in the Aerospace Industry
}

\author{
Richard Farr ${ }^{1}$, David Buxton ${ }^{1}$, Catarina Bovik ${ }^{2}$, Bart MacCarthy ${ }^{1}$, \\ ${ }^{1}$ Business School, University of Nottingham, Nottingham NG8 1BB, UK \\ ${ }^{2}$ Service development \& Customer relations, Volvo Aero Corporation, SE-461 81 Trollhattan, Sweden \\ richard.farr,david.buxton, bart.maccarthy@nottingham.ac.uk; catarina.bovik@volvo.com
}

\begin{abstract}
The virtual enterprise is an ideal solution to the pace of change in modern markets, where increasingly well-informed customers demand high performance, customised products, with continuing downward pressure on prices and lead times. In meeting customer requirements of this kind, the level of investment demanded of an individual manufacturer may be prohibitive, but success can be achieved through collaboration between businesses.

Engineering across organisational boundaries poses many problems, but these have been the subject of study for some years, and are relatively well-supported by systems such as e-business portals, neutral file formats and shared data environments. If lead times are to be further reduced, it may be wise to target the virtual enterprise formation stage, rather than the operations that are to be conducted once the enterprise has formed. Within the VIVACE (Value Improvement through a Virtual Aeronautical Collaborative Enterprise) project, one task is to demonstrate how a significant reduction in the time required for a virtual company to create a business proposal might be achieved. This paper identifies some key obstacles, and discusses potential solutions.
\end{abstract}

Keywords

Virtual enterprise, formation, contractual issues, aerospace

\section{Introduction}

Increasingly, competition is taking place between supply networks rather than between individual businesses [Christopher, 2000], and lead times will be an important basis for competition. Rapid (re-)configuration of the enterprise is necessary when a customer demands something not presently offered, perhaps as a result of their location, with new opportunities arising as the global marketplace develops. Modern aerospace industry offerings comprise not just a range of products and spare parts, but also services that may include financing, insurance, maintenance, leasing, training etc. While presenting desirable business opportunities in the form of a continuing revenue stream, emphasis on product and service increases the complexity of the virtual enterprise, and the importance of decisions at the formation stage.

The complexity of jet engines for modern civil aircraft makes a virtual enterprise approach desirable, allowing a range of core competencies to be applied while sharing the considerable financial burden, and risk. Under conventional business models, new-built engines are typically discounted to the point where they are sold at a loss, in order to acquire market share. The loss is then recouped in the form of charges for spare parts and maintenance work. Newer thinking dictates that the engine should be offered as a comprehensive package that includes a schedule of services; taken to the extreme the new model involves an airline simply paying a fee for the power they use. In either case, the supply of each individual engine involves an investment for the enterprise supplying it, only becoming profitable after a number of years in use. With an inservice life that can be measured in decades, the virtual enterprise must consist of businesses able to work together - and able to improve - throughout a lengthy project. How, then, can an enterprise be 'built to last' when the business proposition that is its raison d'être must be constructed in just a few days? 


\section{Partner Selection}

Weizenboeck [2001] makes a distinction between 'stable' virtual enterprises (long-term entities with a core partner that outsources certain tasks to other businesses) and 'dynamic' enterprises that are formed in response to an invitation from a customer. Virtual enterprises within the aerospace industry will demonstrate some qualities of each; certainly there is a considerable degree of central control, as demanded by aviation certification requirements, but there may also be a certain amount of dynamism, given that a request for a proposal may come from an emerging market where there is little experience or enterprise infrastructure. While the product offering will change relatively slowly, aftermarket requirements may involve a considerable need for agility, particularly as used aircraft and engines are sold on. Those acquiring used engines represent an important segment of the market for spares and services, and must be responded to promptly with an appropriate proposal. What needs to be done to keep the engines in service will be well understood, but who will have a role remains to be determined. This is complicated by the fact that some operators choose to perform certain maintenance and support activities themselves, and the proposal that is drafted must take account of this.

Reithofer and Näger [1997] identify two key issues at the enterprise formation stage: the partner problem and the interface problem. The former is the subject of this paper. Technical, IT-related issues in collaboration are the subject of much research, but collaborative working assumes that a set of enthusiastic partners with the right competencies has been assembled.

A major factor in the success or failure of a virtual enterprise, naturally enough, is the participants themselves. In the aerospace industry the nature and extent of collaboration is typically determined by the prime contractor. In the past, smaller or more highly specialised businesses would have played a simplistic role within the supply chain, selected under criteria such as cost and lead time. An increasingly common alternative is the Risk and Revenue Sharing Partnership (RRSP) where participating businesses become stakeholders, developing new (or improved) products and services, to mutual benefit. If suppliers are to be given more autonomy, however, they must be selected with more care.

Reithofer and Näger [1997] used modelling and simulation aimed at optimising the selection of partners. This assumes, however, that all the qualities and capabilities of each partner can be expressed within a model. While it is possible to establish weightings to reflect the relative importance of issues such as using the software tools as the supplier, or their performance in previous transactions, it must be borne in mind that real-world decisions will be influenced by highly subjective considerations. Examples might include:

- The merit of keeping a certain piece of work in-house in order to retain capability and generate a contribution towards overheads.

- The benefit of obtaining the participation of a certain supplier in order to prevent them from working with a competitor.

- Cultural differences between potential collaborators that might be felt to be a source of friction.

Authors such as Mikhailov [2002] have proposed analytical methods for partner selection, a technique subsequently employed by Wang and Chen [2005], using fuzzy logic to incorporate a representation of the uncertainty found in human decision-makers. Another common approach involves agent-based frameworks (Camarinha-Matos and Afsarmanesh [2003], Ghenniwa et al. [2005]). Such approaches could reduce lead time, since partner selection is one of the activities found on the critical path of virtual enterprise formation, but it is questionable whether these decisions should be left to a computer model, however sophisticated it may be. (Although a partially IT-based solution introduces the possibility of knowledge capture, perhaps allowing choices to be analysed later, improving future decision-making.) 
Furthermore, there is no guarantee that the most desirable partners, as identified by the software tool, will accept the proposition and join the virtual enterprise. (Would the perfect supplier agree you are the perfect customer?) An attractive win-win proposition must first be found, and a significant obstacle to participation lies in the agreements that must be drafted.

\section{Partners' Needs}

If businesses are to collaborate, their needs must be addressed. Managers will need to know that any information they share will be adequately protected (the law being one mechanism for this). They will also need guarantees that other collaborating businesses will achieve what is promised, in terms of throughput, continuing involvement and the performance of any systems they commit to develop. Three forms of risk that commonly influence collaboration decisions in manufacturing and service design are:

- Volume risk (that demand is not as expected, either exceeding business capacity or being too low to pay back development costs),

- Cost risk (that the supply of a product or service proves to be more expensive than was anticipated, placing pressure upon margins), and

- Technical risk (that the product or service, once developed, does not prove to be satisfactory)

To offset these risks, guarantees must be given by each business within the virtual enterprise. This process will begin with the drafting of a letter of intent, which may or may not constitute a legally binding agreement. Mazzeschi [2001] outlines a range of circumstances in which a letter of intent may be required, presenting a scale of different goals, from a binding contract to an exchange of information entirely devoid of sanction. Since an exchange of confidential information is likely to be involved when setting up a virtual enterprise for aerospace, the letter of intent is likely to include protective provisions. Thus, there will be considerable legal input from an early stage. Smaller businesses, if invited to join a virtual enterprise, may be put off from participating if they are required to sign a highly complex legal document before work can begin. Whereas larger businesses can afford to retain a legal staff, smaller ones may find the cost of examining each contract relatively high in terms of the value of business on offer. The detail of the collaborative agreement - when money is to be invested, what activities are to be undertaken, how income is to be apportioned, etc., must of course be analysed by each participant to ensure that the business proposition is acceptable, but extra care must be taken to ensure that the legal agreements entered into match the reasonable expectations of the partners.

With careful checking of contractual documents taking place at every potential collaborator, legal issues require more attention overall than would be required in a conventional business. This is an area of activity where the virtual enterprise is perhaps less efficient than a conventional approach, and must therefore be handled with care as it could be a source of reduced competitiveness. (Legal issues have been addressed by EU integrated projects including eLEGAL, BIDSAVER, MARVIN and ALIVE.) A principal problem with present-day law is that the virtual enterprise does not have a legal identity, and thus no collective responsibility [Cullen, 2000]. Another issue is the nominal location of the virtual organisation, for tax purposes. Furthermore, UK and European contract law assume an adversarial relationship, and this may run contrary to the spirit in which a virtual enterprise is formed, inhibiting flexibility and stifling innovation.

To some degree, it should be possible to represent the activities of all collaborators within a parametric framework that shows a schedule of cash and material movements, gated project reviews and the like. (By no means will this be simple; the authors' investigations unearthed a case where a manufacturer had bought into a risk and revenue sharing partnership despite making no parts on the engine concerned. To compensate, the parts they made for a different 
engine were counted against their contribution.) Any such complexity will naturally complicate the legal agreements that must be drawn up, and the representation of the virtual enterprise in any computer-based decision support system. Still, any formalised system that can show unambiguously the role of each party in the virtual enterprise will allow a degree of automation in the creation of the enterprise, where otherwise each role must be negotiated and set out individually.

One element of the work undertaken by the authors, in order to explore the opportunities of a formalised system, has been to simulate cash flows within the risk and revenue sharing partnerships of an aerospace virtual enterprise. An agent-based model, constructed with the AnyLogic software, allows a variety of scenarios to be explored, including:

- Different partnering agreements, where RRSPs may or may not be extended to second-tier suppliers,

- Alternative levels of adoption, by the airlines, of OEM-provided aftermarket offerings such as TotalCare from Rolls-Royce or MCPH from General Electric,

- Changes in the rate at which new aircraft are ordered, and

- Various aircraft usage patterns.

While it is very difficult to forecast events occurring during a venture that may span fifty years from initial development activities to final decommissioning, models of this kind allow a number of assumptions to be communicated, and tested. (Farr et al [2005] detailed some of the complexity of predictions relating to the future business environment for aerospace.) Allowing cash flows to be explored under a variety of circumstances, this model shows how partners could rapidly evaluate the attractiveness of an invitation to tender, using relatively simple metrics such as net present value, internal rate of return, and maximum project cash negative. Figure 1 shows an illustrative output from the model, in which the break-even point can clearly be seen for a variety of different circumstances.

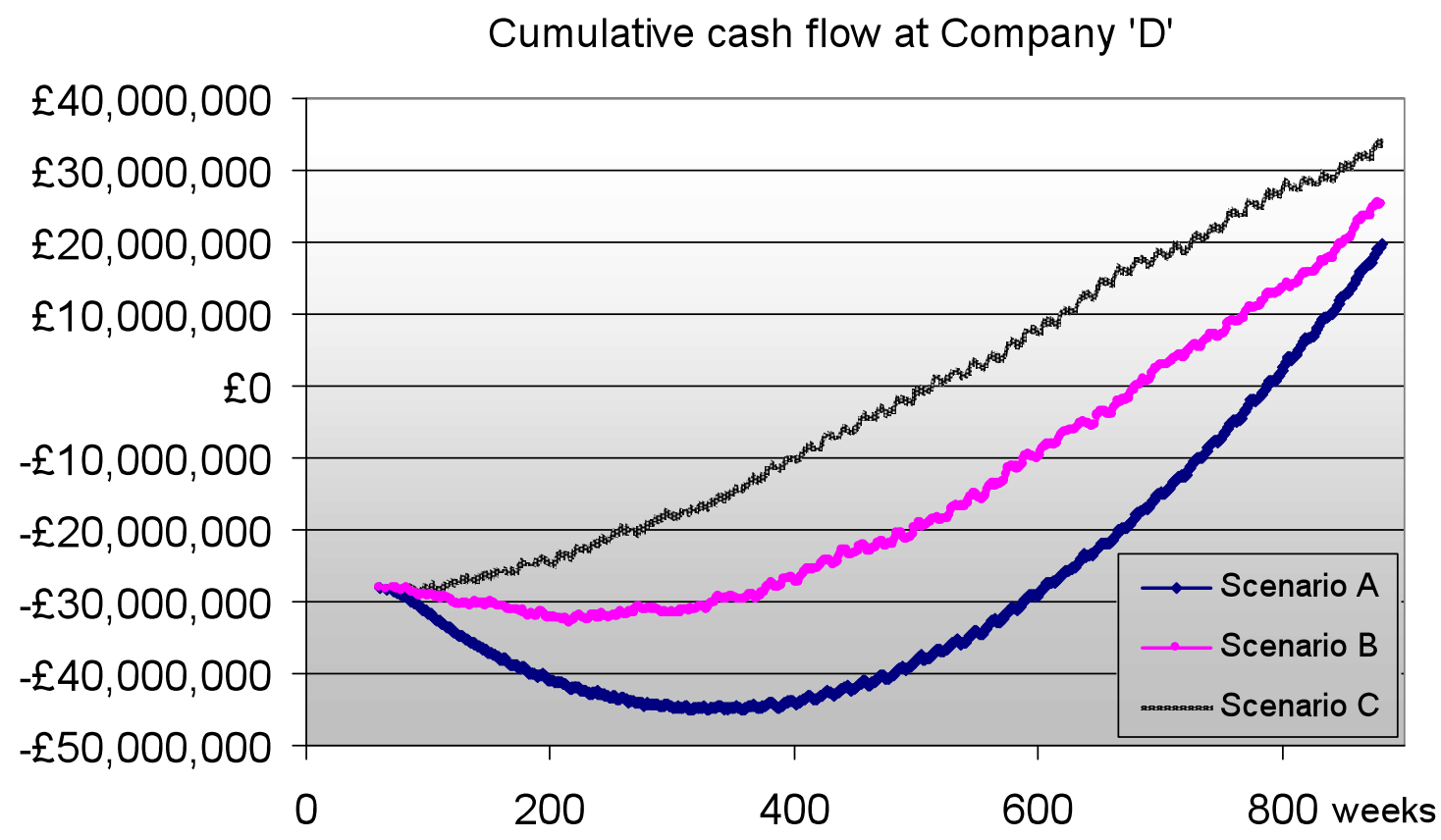

Figure 1: Revenue forecast for three alternative business scenarios

Armed with information from a number of simulations such as this, the company under study could make an informed decision as to whether they ought to investing in the programme as a full risk and revenue sharing partner, or perhaps tender for involvement on a 'build to print' basis... or avoid involvement entirely. 


\section{Discussion}

Information and Communications Technology (ICT) alone does not offer a solution to lead time reduction at the enterprise formation stage. While ICT can offer benefits to the operation of the virtual enterprise once it is up and running, it offers relatively little in the formation stage. Limiting the partner selection process to those that already exist within a database and/or presently comply with a data exchange standard may result in otherwise competitive potential partners being overlooked, and it must be borne in mind that some of the partners will be participating in a number of virtual enterprises at once - not necessarily confined to the aerospace industry. To expect such a partner to adopt new standards or working practices is unreasonable; nor is this conformity always necessary for success. Studying thirty virtual enterprises, Gruber and Nöster [2005] found that just seven employed a common intranet despite the fact that accepted wisdom implies ICT is a major driver of the virtual enterprise. For long-term, stable virtual organisations, the ongoing exchange of information and best practices may lead to changes in working culture and the adoption of common ICT, but the core strength that caused each partner to be selected must not be diluted by the need to conform.

Trust is identified as a key aspect of enterprise formation [Cullen and Hickman, 2001], yet it cannot be measured directly, nor represented adequately in present-day decision support or knowledge capture systems. Legal agreements are more than a substitute for trust, providing an essential risk reduction mechanism, but they need to become more transparent if participation in a rapidly-configured proposal is to become possible for SMEs. To reduce lead time, the virtual enterprise would ideally use standardised documents as far as possible, setting out the activities of each partner in accordance with the entries in a parametric enterprise model. A consortium agreement between the parties that are to make up the virtual enterprise is desirable, rather than a series of individual contracts between suppliers and customers, since the flow-down of information from one supply chain tier to another will otherwise increase lead time. However, attempting to establish the whole network at once will be a much more complicated operation, in management and execution. As a result, consortium agreements may need to be preceded by a relatively informal stage where expressions of 'interest in principle' are obtained. This requires a considerable amount of trust between parties; that discussions take place in confidence, and that proposals are made in earnest, etc. It is to be hoped that this will become increasingly easy when businesses build up a long history of collaboration.

At Volvo Aero Corporation, a detailed study was conducted into the present-day mechanism for proposal generation and the improvements necessary to prepare it for collaborative proposals within a virtual enterprise [Dannemark et al. 2005, Bovik 2006]. A process description was developed, together with a system of tools to guide and support the creation of a proposal. It was additionally concluded that preparations within the virtual enterprise, such as agreeing general principles for co-operation, were an essential feature of a fast proposal process. Figure 2 illustrates the support system concept, with seven information 'silos', each associated with appropriate tools and mechanisms, plus an underlying mutually shared business model and an agreed manner of sharing data, all framed by a culture to promote trust and a shared vision. The simulation model described in Section 3 offers an example of the kind of tool that might feature within the rapid proposal generation process, being useful in the initial preparatory stages, and again in the third silo, addressing the involvement of suppliers. 


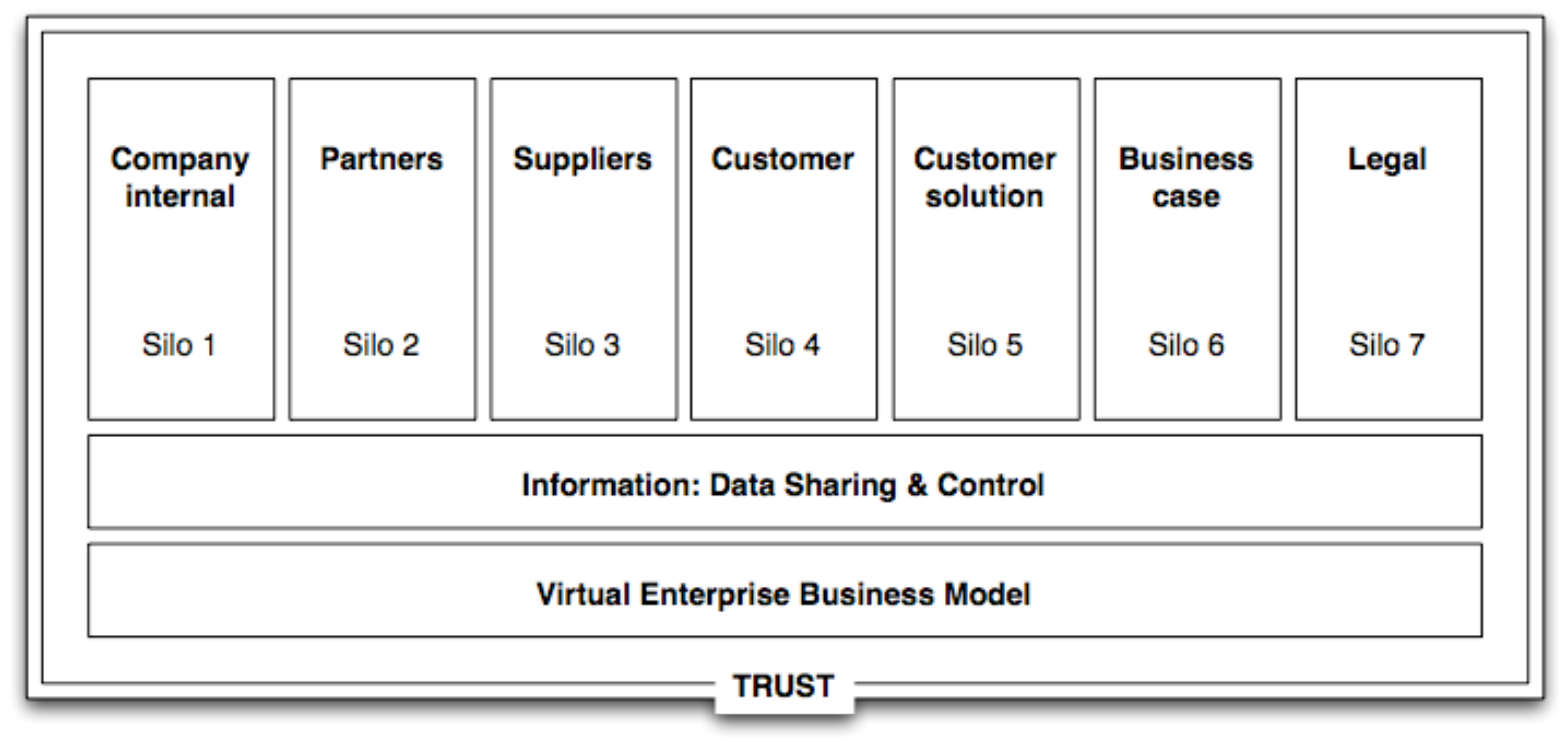

Figure 2: Silos of activity in the proposal generation process [Bovik, 2006]

The modelling activity provided a valuable representation of the proposal generation process, but if further changes were to be made, improvements might lie in continuing to erode the boundaries between the silos. In engineering we have learned that sequential, 'over the wall' information passing results in problematic products - although fully concurrent design is equally impractical, since some decisions must take precedence over others. By mapping the interdependencies between activities, the Volvo Aero model allows a lead time compression strategy similar to that in concurrent engineering to be applied to the creation of a product and service offering. The whole life-cycle of the product can thus be considered by a multifunctional team convened at the design stage. By investing additional effort at the initial stages, cost and time savings are then enjoyed in the remainder of the project.

If a multifunctional team approach could be applied to the design of not merely a virtual enterprise, but to reengineer the process of virtual enterprise formation, what might change? Concurrent engineering provides more principles that can be borrowed:

- Consideration of components whose function might be merged, to reduce complexity

- Focus upon quality and continuous improvement

- The creation of standard modules that can be swapped out when problems arise

- The re-use of proven elements

- Adoption of standard interfaces

Evidence of these principles being employed can already be seen; companies pursue repeat business where they have previously enjoyed a good working relationship, and they seek to share information via common formats, when appropriate. If the legal complexities described in Section 3 could be addressed via standardisation, where appropriate, virtual enterprises could be formed more quickly, could grow more quickly and would be better able to react to problems.

\section{Conclusions}

Allowing a virtual enterprise to be formed faster will be a useful source of competitive advantage in the years to come, but some obstacles remain at this time, not least in terms of the time required to review the implications of any collaborative proposal. The same modularity that has allowed manufacturing businesses to focus upon their strengths and produce some element(s) within a competitive overall product must now be applied to business practices themselves, employing the same good practice in terms of standard interfaces. A key interface at the 
enterprise formation stage is that where agreements are drafted. Not only can this delay proceedings, but complexity here can be a disincentive to participation.

\section{Acknowledgements}

This work has been funded by the European Commission as part of the VIVACE Integrated Project (Sixth Framework Programme contract number AIP3-CT-2003-502917).

\section{References}

Bovik, C. "7 Day Proposal Updated Process and System Requirements" (public project document available from www.vivaceproject.com) April 2006

Camarinha-Matos, L.M. and Afsarmanesh, H. "Elements of a base VE infrastructure", Computers in Industry, Volume 51, 2003, pp 139-163

Christopher, M. "The Agile Supply Chain: Competing in Volatile markets", Industrial marketing Management, Volume 29, Issue 1, Spring 2000, pp 35-57

Cullen, P-A. "Contracting, co-operative relations and extended enterprises" Technovation, Volume 20, 2000 pp $363-372$

Cullen, P-A. and Hickman, R. "Contracting and economics alliances in the aerospace sector: do formal contract arrangements support or impede efficient supply chain relationships?” Technovation, Volume 21, $2001 \mathrm{pp}$ $525-533$

Dannemark, O-J., Bovik, C., and Buxton, D. "7 Day Proposal: Draft Specification of Process, Modelling and Tool Requirements" (public project document available from www.vivaceproject.com) June 2005

Farr, R., Bramham, J., Er, M. and MacCarthy, B. "Scenario Planning in the Aerospace Business Environment - the VIBES Approach", Proceedings of the 11th International Conference on Concurrent Enterprising, 20-22nd June 2005, Munich, Germany.

Ghenniwa, H., Huhns, M.N., and Shen, W. “eMarketplaces for enterprise and cross enterprise integration”, Data \& Knowledge Engineering Volume 52, 2005, pp 33-59

Gruber, M. and Nöster, M. "Investigating Structural Settings of Virtual Organisations", Proceedings of the 11th International Conference on Concurrent Enterprising, 20-22nd June 2005, Munich, Germany

Mazzeschi, M., "The Virtual Organisation”, Proceedings of the 7th International Conference on Concurrent Enterprising, 27-29th June 2001, Bremen, Germany

Mikhailov, L., "Fuzzy analytical approach to partnership selection in formation of virtual enterprises" Omega, Volume 30, Issue 5, October 2002 pp 393-401

Reithofer and Näger "Bottom-up planning approaches in enterprise modelling - the need and the state of the art", Computers in Industry, Volume 33, Issue 2, 1997, pp 223-235

Wang, T-C., and Chen, Y-H., "Applying consistent fuzzy preference relations to partnership selection” Omega, [in press, available online September 9th 2005]

Weitzenboeck, E.M., "Building a Legal Framework for a Virtual Organisation in the Maritime Domain: The MARVIN Experience", Proceedings of the 7th International Conference on Concurrent Enterprising, 27-29th June 2001, Bremen, Germany 